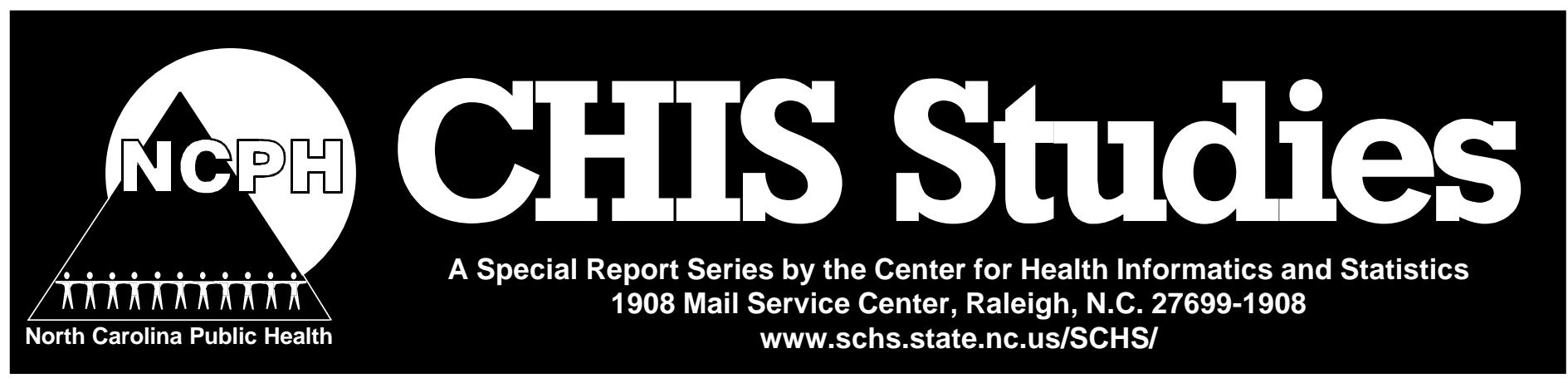

No. 122

November 2000

\title{
Prenatal WIC Participation in Relation to Low Birth Weight and Medicaid Infant Costs in North Carolina - A 1997 Update
}

\author{
by \\ Paul A. Buescher, Ph.D. \\ and \\ Stephanie J. Horton, M.S.
}

\begin{abstract}
Objectives: The purpose of this study is to update and expand a 1988 North Carolina evaluation of prenatal WIC participation, while addressing some potential methodological issues in the earlier study.

Methods: Medicaid and WIC data files were linked to 1997 North Carolina live birth records. Among Medicaid births, birth weight and Medicaid newborn costs were compared between WIC participants and WIC non-participants. Adjustments were made to account for potential biases due to preterm delivery and late entry into the WIC program.

Results: WIC non-participants were significantly more likely than WIC participants to have low-weight births and, on average, their newborn Medicaid costs were higher. These general results persisted after adjustments for the potential biases due to preterm delivery and late entry into WIC. After adjustments, we estimate that, overall, at least one dollar was saved in Medicaid newborn costs for every dollar spent for prenatal WIC services. Cost savings were higher for births to minority women compared to white women.
\end{abstract}

Conclusions: The positive findings for prenatal WIC participation from the 1988 study are generally confirmed in the present study. Improved health of babies is a valuable benefit resulting from the prenatal WIC program. 


\section{Introduction}

The Special Supplemental Nutrition Program for Women, Infants, and Children (WIC) is funded by the United States Department of Agriculture and provides supplemental food and nutrition education to low-income pregnant, postpartum, or lactating women and infants and young children who are nutritionally at risk. The WIC program also encourages the use of appropriate health care. Several previous studies have found that prenatal WIC participation is associated with improved birth outcomes and reduced infant medical costs. ${ }^{1,2,3,4}$ One of these studies was done in North Carolina using data on 1988 live births to women on Medicaid. ${ }^{1}$ The purpose of the present study is to replicate and expand the 1988 North Carolina results for the 1997 birth year, while addressing some potential methodological issues in the earlier study.

\section{Methods}

Medicaid paid claims for newborn hospitalizations were matched to 1997 live birth certificates to identify the population of Medicaid births. The Medicaid ID numbers of these newborns were used to retrieve their medical claims paid by Medicaid during the first 60 days of life. Costs for services beginning in the first 60 days of life were summarized for each Medicaid birth. WIC prenatal records were linked to the 1997 birth certificates to identify the women on Medicaid who participated in WIC before delivery. Using the WIC ID numbers for these women, we linked to the WIC food redemption files to determine the date of the first redemption and the cost of food vouchers redeemed during the pregnancy. The total WIC prenatal program cost was calculated as the value of the food vouchers redeemed plus nutrition services and administrative costs of $\$ 9.50$ per participant per month.

Within the Medicaid births, women participating in WIC were compared to women not participating in WIC. The results are stratified for white and minority births, since race is a strong risk factor for low birth weight. Approximately 90 percent of minority births in North Carolina are to African Americans. During 1997, the income eligibility level for pregnant women and their infants for both Medicaid and WIC in North Carolina was 185 percent of the federal poverty level. Births with no prenatal care were excluded, as in the 1988 study, since nearly all would fall in the non-WIC group, resulting in poorer birth outcomes in this comparison group. Multiple births (less than three percent of all births) were excluded from this study due to their very high rate of low birth weight, which could skew the results. Births resulting in an infant death are included, unless excluded because of no prenatal care or multiple birth. Simple comparisons of low birth weight $(<2,500$ grams $)$ and very low birth weight $(<1,500$ grams $)$ were supplemented by regression analyses, to determine the effect of prenatal WIC participation on birth weight while controlling for other risk factors.

The difference in average Medicaid newborn costs between babies of prenatal WIC participants and WIC non-participants was compared to the average prenatal WIC program cost, to estimate any cost savings. The difference in average Medicaid costs between the WIC and non-WIC groups was also estimated using regression analysis, which controlled for other measurable factors that might impact Medicaid costs.

Comparisons are made to the 1988 study with WIC participation defined as one or more WIC encounters during the prenatal period. The earlier study recognized that if a woman does not enter WIC until very late in pregnancy, there is a high probability she will have a normal birth weight baby just due to the length of gestation, yet she is counted in the WIC group. The 1988 study attempted to control for this bias by counting women who started WIC after 36 weeks gestation in the non-WIC group. This approach did not alter the results substantially. In the present study we added analyses to address this issue, adopting a more stringent criterion where women who started WIC at 33 or more weeks of gestation were counted in the non-WIC group. Leaving these moderately preterm births (33 to 36 weeks) in the WIC group might favor a positive 
finding for prenatal WIC participation, since some of these births could have relatively high birth weights.

Another potentially serious problem in evaluations of prenatal services is the preterm delivery bias. Women who have a very early delivery may never have a chance to enroll in WIC. One study ${ }^{5}$ used "cohort analyses" to address this problem and we have adopted that approach here. Three cohorts were defined (29, 33, and 37 weeks gestation) and the logistic regression analyses for low birth weight and very low birth weight were repeated with all births occurring before the specified week of gestation excluded from the analysis. This approach measures the effect of prenatal WIC participation on birth weight only for those pregnancies with a gestational age greater than or equal to the cutoff point.

Finally, to address possible gestational age bias, we repeated some of the regression analyses using weeks of gestation as a control variable in the model. This approach will estimate the effect of WIC on birth weight, controlling for gestational age. That is, estimated coefficients can be interpreted as the effect of prenatal WIC participation on birth weight at a given gestation.

\section{Results}

Table 1 shows that, among 1997 Medicaid births in North Carolina, women who participated in WIC during the prenatal period had significantly lower

Table 1.

Percentages of low and very low birth weight and selected maternal prenatal risk factors among live births to North Carolina women receiving Medicaid benefits in $1997^{\mathrm{a}}$ by race and maternal participation in the Special Supplemental Nutrition Program for Women, Infants, and Children (WIC)

\begin{tabular}{|c|c|c|c|c|c|c|}
\hline \multirow[b]{2}{*}{ Risk factor } & \multicolumn{2}{|c|}{ Total } & \multicolumn{2}{|c|}{ White } & \multicolumn{2}{|c|}{ Minority } \\
\hline & $\begin{array}{c}W^{W^{b}} \\
(n=33,080)\end{array}$ & $\begin{array}{c}\text { non-WIC } \\
(n=10,196)\end{array}$ & $\begin{array}{c}\text { WIC }^{b} \\
(n=17,481)\end{array}$ & $\begin{array}{l}\text { non-WIC } \\
(n=6,529)\end{array}$ & $\begin{array}{c}\text { WIC }^{b} \\
(n=15,599)\end{array}$ & $\begin{array}{l}\text { non-WIC } \\
(n=3,667)\end{array}$ \\
\hline $\begin{array}{l}\text { Low birth weight } \\
<2500 \mathrm{~g} \\
<1500 \mathrm{~g}\end{array}$ & $\begin{array}{l}8.8 \\
1.5\end{array}$ & $\begin{array}{r}10.5^{\star} \\
2.5^{\star}\end{array}$ & $\begin{array}{l}6.9 \\
0.9\end{array}$ & $\begin{array}{l}8.4^{*} \\
2.0^{*}\end{array}$ & $\begin{array}{r}10.9 \\
2.1\end{array}$ & $\begin{array}{r}14.2^{*} \\
3.5^{\star}\end{array}$ \\
\hline \multicolumn{7}{|l|}{ Maternal risk factors } \\
\hline $\begin{array}{l}\text { Unmarried } \\
\text { Education<12 vears }\end{array}$ & $\begin{array}{l}61.8 \\
40.8\end{array}$ & $\begin{array}{l}45.5 \\
37.0\end{array}$ & $\begin{array}{l}45.3 \\
45.5\end{array}$ & $\begin{array}{l}33.3 \\
40.4\end{array}$ & $\begin{array}{l}80.2 \\
35.7\end{array}$ & $\begin{array}{l}67.1 \\
30.9\end{array}$ \\
\hline Age $<18$ years & 12.0 & 7.8 & 10.4 & 7.6 & 13.7 & 8.0 \\
\hline $\begin{array}{l}\text { Previous fetal death or live } \\
\text { born who died }\end{array}$ & 27.4 & 27.0 & 25.4 & 24.6 & 29.7 & 31.2 \\
\hline $\begin{array}{l}\text { Less than adequate prenatal } \\
\text { care }^{c}\end{array}$ & 30.3 & 35.9 & 26.1 & 30.6 & 35.1 & 45.4 \\
\hline Smoke cigarettes & 23.9 & 22.4 & 32.2 & 25.4 & 14.6 & 17.1 \\
\hline $\begin{array}{l}\text { One or more medical risk } \\
\text { factors on birth certificate }\end{array}$ & 33.2 & 31.5 & 30.0 & 29.0 & 36.9 & 36.0 \\
\hline $\begin{array}{l}\text { No Medicaid case } \\
\text { management }\end{array}$ & 41.4 & 82.5 & 47.9 & 87.8 & 34.1 & 73.1 \\
\hline \multicolumn{7}{|c|}{$\begin{array}{l}\text { Births to mothers who received no prenatal care and multiple births are excluded. } \\
\text { bother was a WIC participant at some time during pregnancy. } \\
\text { cAdequacy of prenatal care determined using the Kessner index. } \\
\text { cThese risk factors include anemia, cardiac disease, diabetes, hypertension, eclampsia, renal disease, and previous preterm infant } \\
\text { (same as in } 1988 \text { study). } \\
\text { *Significant }(P<.001) \text { difference between WIC and non-WIC groups. }\end{array}$} \\
\hline
\end{tabular}


rates of low and very low birth weight than women who did not participate in WIC. The women who participated in WIC were more likely than those who did not participate to be unmarried, of low education, and under age 18. Also, the WIC group was substantially more likely to have a quantitatively adequate level of prenatal care and to have received Medicaid case management services during pregnancy. The logistic regression analyses in Table 2 confirm the findings from Table 1 of lower rates of low and very low birth weight among the WIC births. Women who did not participate in WIC have an odds of low birth weight 1.36 times that of the women who did participate in WIC, controlling for other risk factors for low birth weight. The adjusted odds ratio for very low birth weight for the WIC non-participants was 1.90. An ordinary least squares regression with grams of birth weight as a continuous dependent variable also showed a statistically significant positive effect for WIC. After controlling for the risk factors shown in Table 2 , WIC non-participation was associated with an average 61 grams lower birth weight $(\mathrm{p}=.0001)$.

Table 3 suggests that $\$ 1.99$ was saved in newborn Medicaid costs (for services beginning within 60 days of birth) for every dollar spent by WIC in the prenatal period. These cost savings figures are $\$ 1.44$ for white births and $\$ 4.02$ for minority births. Using regression analysis to determine an adjusted cost difference between WIC and non-WIC births produces higher cost savings estimates for white and total Medicaid births (Table 3, last column). This change is consistent with the finding that the WIC group is at higher risk for low birth weight on several of the demographic characteristics; adjusting for these characteristics in effect reduces the cost estimates for the WIC group.

Table 2.

Adjusted odds ratios (ORs) from logistic regression and 95\% confidence intervals (Cls) for selected maternal risk factors for low birth weight among 42,965 live births to North Carolina women receiving Medicaid benefits in $1997^{\text {a }}$

\begin{tabular}{|c|c|c|c|c|}
\hline \multirow[b]{2}{*}{ Risk factors } & \multicolumn{2}{|c|}{$\begin{array}{c}\text { Low } \\
\text { birth weight } \\
(<2500 \mathrm{~g})\end{array}$} & \multicolumn{2}{|c|}{$\begin{array}{l}\text { Very low } \\
\text { birth weight } \\
(<1500 \mathrm{~g})\end{array}$} \\
\hline & OR & $\mathrm{Cl}$ & OR & $\mathrm{Cl}$ \\
\hline $\begin{array}{l}\text { One or more medical risk } \\
\text { factors on birth certificate }^{b}\end{array}$ & 2.66 & $2.49,2.85$ & 4.71 & $4.02,5.53$ \\
\hline Minority status & 1.63 & $1.51,1.76$ & 1.85 & $1.57,2.19$ \\
\hline Smoked cigarettes & 1.68 & $1.55,1.80$ & 1.29 & $1.09,1.54$ \\
\hline Not enrolled in WICc & 1.36 & $1.26,1.48$ & 1.90 & $1.61,2.25$ \\
\hline $\begin{array}{l}\text { Previous fetal death or live } \\
\text { born who died }\end{array}$ & 1.22 & $1.13,1.31$ & 1.50 & $1.28,1.75$ \\
\hline Age $<18$ years & 1.12 & $1.00,1.25$ & 1.36 & $1.05,1.76$ \\
\hline $\begin{array}{l}\text { No Medicaid case } \\
\text { management }\end{array}$ & 0.98 & $0.91,1.06$ & 1.14 & $0.97,1.34$ \\
\hline $\begin{array}{l}\text { Less than adequate } \\
\text { prenatal care }^{d}\end{array}$ & 1.21 & $1.13,1.30$ & 1.04 & $0.89,1.22$ \\
\hline Education $<12$ years & 1.15 & $1.07,1.24$ & 0.91 & $0.77,1.08$ \\
\hline Unmarried & 1.13 & $1.04,1.22$ & 1.22 & $1.03,1.45$ \\
\hline \multicolumn{5}{|c|}{$\begin{array}{l}\text { aBirths to mothers who received no prenatal care and multiple births are excluded. Records with missing values for any } \\
\text { variable are excluded. } \\
\text { bThese risk factors include anemia, cardiac disease, diabetes, hypertension, eclampsia, renal disease, and previous } \\
\text { preterm infant (same as in } 1988 \text { study). } \\
\text { cMother was not enrolled in WIC at all during pregnancy. } \\
\text { dAdequacy of prenatal care determined using the Kessner index. }\end{array}$} \\
\hline
\end{tabular}


Table 3.

Average costs to Medicaid for newborn services beginning within 60 days of birth and average costs of WIC services for 44,409 infants born to North Carolina women receiving Medicaid benefits in $1997^{\text {a }}$ by race and maternal participation in the Special Supplemental Nutrition Program for Women, Infants, and Children (WIC)

\begin{tabular}{|c|c|c|c|c|c|c|c|}
\hline & \multicolumn{4}{|c|}{ Medicaid costs (\$) } & \multirow[b]{2}{*}{$\begin{array}{l}\text { WIC costs } \\
\text { (\$) }\end{array}$} & \multirow[b]{2}{*}{$\begin{array}{l}\text { Benefit to } \\
\text { cost ratio }\end{array}$} & \multirow{2}{*}{$\begin{array}{l}\text { Adjusted } \\
\text { benefit to } \\
\text { cost ratio }\end{array}$} \\
\hline & WIC ${ }^{b}$ & non-WIC & Difference & $\begin{array}{l}\text { Adjusted } \\
\text { difference }^{\mathrm{c}}\end{array}$ & & & \\
\hline White & 2,354 & 2,702 & 348 & 462 & 242 & 1.44 & 1.91 \\
\hline Minority & 3,085 & 4,005 & 920 & 901 & 229 & 4.02 & 3.93 \\
\hline Total & 2,699 & 3,170 & 471 & 628 & 236 & 1.99 & 2.66 \\
\hline
\end{tabular}

aBirths to mothers who received no prenatal care and multiple births are excluded.

${ }^{\mathrm{b}}$ Mother was a WIC participant at some time during pregnancy.

'Based on multiple regression analysis, controlling for other predictors of cost shown in Table 2.

dWIC costs include administrative and food costs.

eDifference divided by WIC costs.

${ }^{\dagger}$ Adjusted difference divided by WIC costs.

Tables 4, 5, and 6 repeat these analyses where births with WIC participation beginning at 33 or more weeks of gestation were counted in the non-WIC group. As expected, the differences are reduced. Table 4 shows that women who participated in prenatal WIC by 33 weeks of gestation generally had significantly lower rates of low birth weight and very low birth weight than women who did not participate in WIC or began WIC late in pregnancy. Only the very low birth weight difference for minority births was not statistically significant $(\mathrm{p}<.05)$. Again, the WIC group had higher percentages unmarried, with low education, and under age 18. The women who began WIC prior to 33 weeks gestation were considerably more likely than the comparison group to have quantitatively adequate prenatal care and receive Medicaid prenatal case management services. The logistic regression analyses in Table 5 indicate that late or no participation in WIC is associated with higher rates of low and very low birth weight, when other risk factors are statistically controlled. These odds ratios are statistically significant.

Table 6, where WIC is defined as participation by 33 weeks of gestation, shows lower newborn cost savings associated with WIC, compared with Table 3. The average WIC program costs are somewhat higher than those shown in Table 3, since births where WIC began late in pregnancy are no longer included in the WIC group. WIC participation is still associated with lower Medicaid newborn costs, but, overall, the apparent savings are not more than the amount expended by WIC. For total births, the results in Table 6 suggest that $\$ 0.56$ was saved in newborn Medicaid costs for every dollar spent by the WIC program for prenatal services. For minority births, however, these results show a savings in expenditures for newborn medical care of $\$ 1.26$ for every dollar spent by WIC for prenatal services. Using the adjusted cost difference between early WIC and all other births (from regression analysis), the Medicaid savings associated with WIC participation are estimated at approximately one dollar for every dollar spent on WIC prenatal services (Table 6, last column).

Table 7 presents the adjusted odds ratios for WIC non-participation for each of the three gestational age cohorts. Among births that reached 29 or 33 weeks gestation, the odds of low birth weight and very low birth weight are significantly higher for WIC non-participants compared to WIC participants. In the 37-week cohort, neither of the odds ratios are statistically significant. However, there were only 28 very low birth weight births in this 
Table 4.

Percentages of low and very low birth weight and selected maternal prenatal risk factors among live births to North Carolina women receiving Medicaid benefits in $1997^{\text {a }}$ by race and maternal participation in the Special Supplemental Nutrition Program for Women, Infants, and Children (WIC)

\begin{tabular}{|c|c|c|c|c|c|c|}
\hline \multirow[b]{2}{*}{ Risk factor } & \multicolumn{2}{|c|}{ Total } & \multicolumn{2}{|c|}{ White } & \multicolumn{2}{|c|}{ Minority } \\
\hline & $\begin{array}{c}\text { Early } \\
\text { WIC }^{b} \\
(n=30,173)\end{array}$ & $\begin{array}{c}\text { Late or } \\
\text { no WIC } \\
(n=13,103)\end{array}$ & $\begin{array}{c}\begin{array}{c}\text { Early } \\
\text { WIC }^{b} \\
(n=15,903)\end{array} \\
\end{array}$ & $\begin{array}{c}\text { Late or } \\
\text { no WIC } \\
(n=8,107)\end{array}$ & $\begin{array}{c}\begin{array}{c}\text { Early } \\
\text { WIC }^{b} \\
(n=14,270)\end{array} \\
\end{array}$ & $\begin{array}{c}\text { Late or } \\
\text { no WIC } \\
(n=4,996)\end{array}$ \\
\hline $\begin{array}{l}\text { Low birth weight } \\
<2500 \mathrm{~g} \\
<1500 \mathrm{~g}\end{array}$ & $\begin{array}{l}9.0 \\
1.6\end{array}$ & $\begin{array}{l}9.6^{*} \\
2.1^{*}\end{array}$ & $\begin{array}{l}7.0 \\
1.0\end{array}$ & $\begin{array}{l}7.8^{*} \\
1.6^{*}\end{array}$ & $\begin{array}{r}11.2 \\
2.3\end{array}$ & $\begin{array}{c}12.4^{*} \\
2.8\end{array}$ \\
\hline \multicolumn{7}{|l|}{ Maternal risk factors } \\
\hline Unmarried & 61.6 & 49.4 & 45.1 & 36.0 & 80.1 & 71.2 \\
\hline Education $<12$ years & 41.1 & 37.1 & 45.9 & 40.5 & 35.9 & 31.7 \\
\hline Age $<18$ years & 12.1 & 8.3 & 10.5 & 8.0 & 14.0 & 8.8 \\
\hline $\begin{array}{l}\text { Previous fetal death of } \\
\text { live born who died }\end{array}$ & 27.4 & 27.1 & 25.4 & 24.6 & 29.6 & 31.1 \\
\hline $\begin{array}{l}\text { Less than adequate } \\
\text { prenatal care }\end{array}$ & 29.0 & 37.6 & 25.0 & 31.7 & 33.4 & 47.3 \\
\hline Smoke cigarettes & 23.7 & 23.1 & 32.1 & 26.9 & 14.4 & 17.0 \\
\hline $\begin{array}{l}\text { One or more medical } \\
\text { risk factors on birth } \\
\text { certificate }^{d}\end{array}$ & 33.6 & 31.1 & 30.3 & 28.6 & 37.3 & 35.1 \\
\hline $\begin{array}{l}\text { No Medicaid case } \\
\text { management }\end{array}$ & 39.6 & 77.4 & 46.2 & 82.8 & 32.3 & 67.4 \\
\hline \multicolumn{7}{|c|}{$\begin{array}{l}\text { aBirths to mothers who received no prenatal care and multiple births are excluded. Records with missing values for any variable are } \\
\text { excluded. } \\
\text { "Early WIC means that the mother was a WIC participant by the 33rd week of gestation. } \\
\text { 'Adequacy of prenatal care determined using the Kessner index. } \\
\text { oThese risk factors include anemia, cardiac disease, diabetes, hypertension, eclampsia, renal disease, and previous preterm infant } \\
\text { (same as in } 1988 \text { study). } \\
\text { } \text { Significant ( }(P<.05) \text { difference between WIC and non-WIC groups. }\end{array}$} \\
\hline
\end{tabular}

cohort, compared to 742 in the full regression models in Tables 2 and 5.

The logistic regression analyses in Table 2 were repeated, adding weeks of gestation as a control variable in the models. For both low birth weight and very low birth weight, the odds ratios for WIC non-participation were no longer statistically significant. This suggests that gestational age bias may be an important issue. Alternatively, it may be that most of the effect of prenatal WIC participation in increasing birth weight is through lengthening gestation. However, an ordinary least squares regression with grams of birth weight as a continuous dependent variable did show a statistically significant positive effect for WIC. After controlling for weeks of gestation and also the other risk factors shown in Table 2, WIC non-participation was associated with an average 17 grams lower birth weight $(\mathrm{p}=.006)$. This suggests that there is some effect of prenatal WIC participation in increasing birth weight at each week of gestation. These results are consistent with those of the National WIC Evaluation, which found that prenatal WIC participation was associated with increased birth weight and a longer duration of gestation. ${ }^{6}$ 
Table 5.

Adjusted odds ratios (ORs) from logistic regression and 95\% confidence intervals (Cls) for selected maternal risk factors for low birth weight among 42,965 live births to North Carolina women receiving Medicaid benefits in 1997ª

\begin{tabular}{|c|c|c|c|c|}
\hline \multirow[b]{2}{*}{ Risk factors } & \multicolumn{2}{|c|}{$\begin{array}{c}\text { Low } \\
\text { birth weight } \\
(<2500 \mathrm{~g})\end{array}$} & \multicolumn{2}{|c|}{$\begin{array}{c}\text { Very low } \\
\text { birth weight } \\
(<1500 \mathrm{~g})\end{array}$} \\
\hline & OR & Cl & OR & $\mathrm{Cl}$ \\
\hline $\begin{array}{l}\text { One or more medical risk } \\
\text { factors on birth certificate }\end{array}$ & 2.67 & $2.50,2.86$ & 4.74 & $4.04,5.56$ \\
\hline Black race & 1.63 & $1.51,1.75$ & 1.83 & $1.55,2.17$ \\
\hline Smoked cigarettes & 1.67 & $1.55,1.81$ & 1.29 & $1.09,1.54$ \\
\hline Not enrolled in WIC & 1.14 & $1.06,1.24$ & 1.38 & $1.17,1.62$ \\
\hline $\begin{array}{l}\text { Previous fetal death or live } \\
\text { born who died }\end{array}$ & 1.22 & $1.13,1.31$ & 1.50 & $1.28,1.75$ \\
\hline Age $<18$ years & 1.11 & $0.99,1.25$ & 1.34 & $1.03,1.74$ \\
\hline $\begin{array}{l}\text { No Medicaid case } \\
\text { management }\end{array}$ & 1.03 & $0.96,1.11$ & 1.25 & $1.07,1.47$ \\
\hline $\begin{array}{l}\text { Less than adequate } \\
\text { prenatal care }^{d}\end{array}$ & 1.22 & $1.13,1.31$ & 1.06 & $0.90,1.24$ \\
\hline Education $<12$ years & 1.15 & $1.07,1.24$ & 0.92 & $0.77,1.09$ \\
\hline Unmarried & 1.11 & $1.03,1.20$ & 1.18 & $1.00,1.40$ \\
\hline \multicolumn{5}{|c|}{$\begin{array}{l}\text { aBirths to mothers who received no prenatal care and multiple births are excluded. Records with missing values for any } \\
\text { variable are excluded. } \\
\text { bThese risk factors include anemia, cardiac disease, diabetes, hypertension, eclampsia, renal disease, and previous } \\
\text { preterm infant (same as in } 1988 \text { study). } \\
\text { cNot enrolled in WIC by } 33 \text { rd week of gestation. } \\
\text { dAdequacy of prenatal care determined using the Kessner index. }\end{array}$} \\
\hline
\end{tabular}

Table 6.

Average costs to Medicaid for newborn services beginning within 60 days of birth and average costs of WIC services for 44,409 infants born to North Carolina women receiving Medicaid benefits in $1997^{\text {a }}$ by race and maternal participation in the Special Supplemental Nutrition Program for Women, Infants, and Children (WIC)

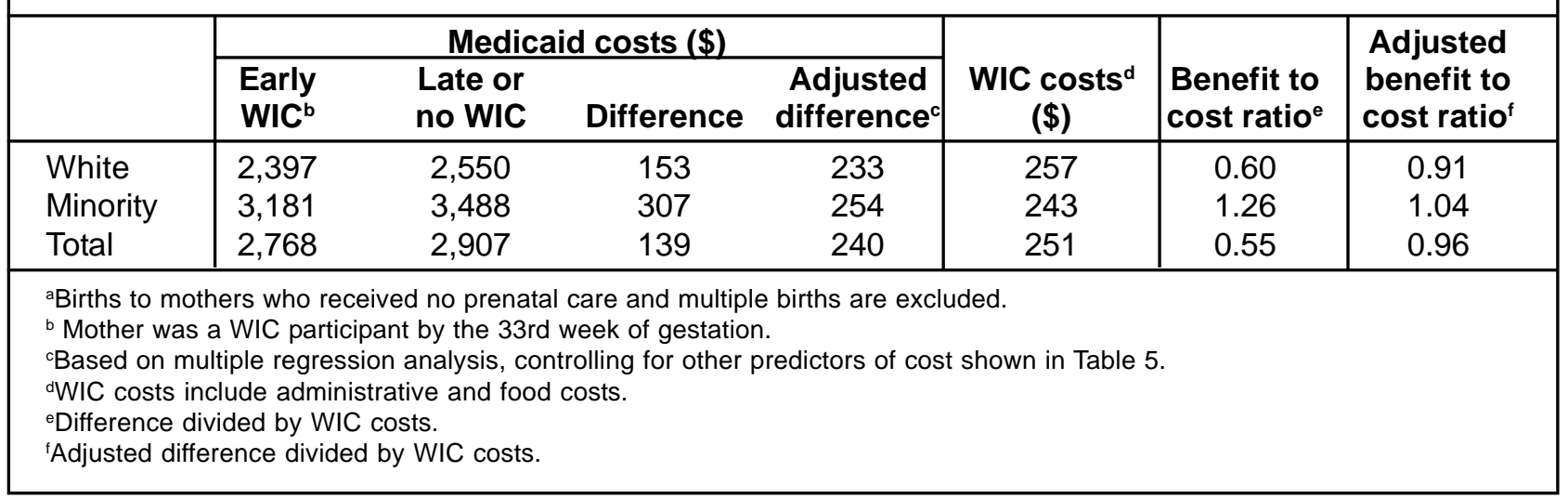


Table 7.

Adjusted odds ratios (OR) from logistic regression and 95\% confidence intervals (Cls) for non-WIC participants ${ }^{a}$ among live births to North Carolina women receiving Medicaid benefits in 1997: cohort analyses ${ }^{b}$

\begin{tabular}{|l|lr|rr|c|}
\hline \multirow{2}{*}{$\begin{array}{l}\text { Cohort: all deliveries } \\
\text { prior to specified weeks } \\
\text { of gestation are excluded }\end{array}$} & Low birth weight & Very low birth weight & \multirow{2}{*}{ Number of births } \\
\cline { 2 - 5 } & OR & Cl & OR & Cl & Numb \\
\hline 29 weeks & 1.28 & $1.17,1.39$ & 1.66 & $1.30,2.11$ & 42,544 \\
33 weeks & 1.20 & $1.09,1.31$ & 1.57 & $1.02,2.40$ & 41,757 \\
37 weeks & 1.06 & $0.93,1.22$ & 1.81 & $0.77,4.28$ & 37,396 \\
\hline
\end{tabular}

\section{Discussion}

In the absence of a randomized study, it is difficult to measure precisely the improvements in birth outcomes and savings in newborn Medicaid expenditures associated with prenatal WIC participation. In the regression analyses we controlled for measurable differences between the WIC and non-WIC groups, but selection bias may still result in unmeasured differences between the two groups that operate in favor of WIC. We tried several methods to adjust for possible biases associated with gestational age, and these results generally confirmed the positive effects of WIC found in the initial analyses.

The inclusion of infant deaths may affect the cost estimates. Approximately half of infant deaths occur in the first day of life. Since the non-WIC group has a higher rate of low birth weight, and low birth weight babies are much more likely to die as infants, the newborn costs for the non-WIC group may be reduced. A comparison of costs only among surviving infants might show a larger cost difference in favor of the prenatal WIC participants.
This study considered cost savings only in the first 60 days of life. Payments for services beginning in the first 60 days of life were counted, so all of the costs of a lengthy newborn hospitalization would be included. However, a study by the General Accounting Office ${ }^{7}$ estimates that approximately 60 percent of the total excess costs of low birth weight up to age 18 result from the initial hospitalization. Other significant costs associated with low birth weight are rehospitalization and other medical costs after 60 days of age, long-term disability costs, and special education costs. These additional costs are not measured in the present study, and so the cost savings of WIC shown here likely underestimate the total cost savings over a longer period of time.

The earlier evaluation of prenatal WIC participation in North Carolina was for 1988, a time when the income level for Medicaid eligibility for pregnant women was 100 percent of the federal poverty level. In 1997, the year of this study, pregnant women were eligible for Medicaid at 185 percent of the federal poverty level. As a result, the number of live births to women enrolled in Medicaid nearly doubled to more than 43,000 in the present study. There is some evidence that prenatal WIC is 
more effective at the lowest income levels. ${ }^{7}$ The estimated WIC effects in Tables 1-3 (before adjustments for preterm delivery and late entry into the WIC) were somewhat less than the comparable effects from the 1988 study. The higher average income level of the women in the present study could contribute to this difference.

Overall, the results here suggest that prenatal participation in WIC among women enrolled in Medicaid is associated with reduced rates of low and very low birth weight, and with lower infant Medicaid costs. Cost savings were higher for births to minority women compared to white women. Although the methodological difficulties have not been completely resolved, the positive findings for WIC from the 1988 study are generally confirmed in this study. In addition to having better birth outcomes and lower infant costs, the women who participated in WIC were more likely than those who did not participate to have a quantitatively adequate level of prenatal care and to have received Medicaid case management services during pregnancy.

The question has been raised whether cost savings is the most appropriate criterion by which to judge prenatal care programs. ${ }^{8}$ It is sometimes assumed that in order for these programs to be valuable, they should save more than they cost. Improved health of mothers and babies is a valuable benefit in itself and society should be willing to commit resources toward this goal.

\section{Acknowledgments}

The authors would like to thank Barbara Devaney of Mathematica Policy Research, Inc. and Jay Hirschman and Janet Schiller of the U.S. Department of Agriculture for helpful comments on this paper.

\section{References}

1. Buescher PA, Larson LC, Nelson MD, Lenihan AJ. Prenatal WIC participation can reduce low birth weight and newborn medical costs: a costbenefit analysis of WIC participation in North Carolina. Journal of the American Dietetic Association 1993; 93:163-166.

2. Schramm WF. WIC prenatal participation and its relationship to newborn Medicaid costs in Missouri: a cost/benefit analysis. American Journal of Public Health 1985; 75:851-857.

3. Schramm WF. Prenatal participation in WIC related to Medicaid costs for Missouri newborns: 1982 update. Public Health Reports 1986; 101:607-615.

4. Mathematica Policy Research Inc. The savings in Medicaid costs for newborns and their mothers from prenatal participation in the WIC program. Washington D.C.: Food and Nutrition Service, U.S. Department of Agriculture, 1990.

5. Tyson J, Guzick D, Rosenfeld CR, Lasky R, Gant N, Jiminez J, Heartwell S. Prenatal care evaluation and cohort analyses. Pediatrics 1990; 85:195-204.

6. Rush D, Alvir JM, Kenny DA, Johnson SS, Horvitz DG. Historical study of pregnancy outcomes. American Journal of Clinical Nutrition 1988; 48:412-428.

7. U. S. General Accounting Office. Early intervention: federal investments like WIC can produce savings. April 1992. Publication No. GAO/HRD-92-18.

8. Huntington J, Connell FA. For every dollar spent - the cost-savings argument for prenatal care. The New England Journal of Medicine 1994; 331:1303-1307. 


\section{thes \\ State of North Carolina \\ Department of Health and Human Services \\ State Health Director}

A. Dennis McBride, M.D., M.P.H.

Division of Public Health

\section{Center for Health Informatics and Statistics}

John M. Booker, Ph.D., Director

www.schs.state.nc.us/SCHS/

The NC Department of Health and Human Services does not discriminate on the basis of race, color, national origin, sex, religion, age or disability in employment or the provision of services. 